\title{
Formação para o atendimento educacional especializado: a constituição do sujeito pelo endividamento da maximum capacity
}

\author{
Daiana Bastos da Silva Santos ${ }^{1}$ \\ Helena Venites Sardagna ${ }^{2}$
}

\section{Resumo}

O artigo analisa a estratégia de formação continuada para o atendimento educacional especializado (AEE) e suas implicações, no âmbito dos estudos de formação continuada de professores para o AEE, a partir de quatro municípios da região Litoral Norte/RS. Os dados foram coletados em entrevistas semiestruturadas, realizadas com professores do AEE desses municípios. Como apontamentos, o estudo problematiza a constituição de uma nova figura subjetiva contemporânea - o sujeito docente da maximum capacity - por meio de uma racionalidade neoliberal, na esteira da noção metodológica foucaultiana de biopolítica. O professor participante da pesquisa, ao buscar a formação continuada, é interpelado pela lógica do desempenho, sentindo-se responsável pela gestão da sua formação.

Palavras-chave: Formação Continuada; Atendimento Educacional Especializado; Maximum Capacity; Subjetivação.

\section{Formation for the specialized educational service: the constitution of the subject by indebtedness of the maximum capacity}

\begin{abstract}
The study analyzed the strategy of continuing education for the Specialized Educational Service (SES), seeking to understand its implications in the context researched, in four municipalities in the North Coast / RS region. The data were collected in semi-structured interviews with SES teachers from these regions. The present work problematizes the constitution of a new contemporary subjective figure - the teacher of maximum capacity - through a neoliberal rationality, in the wake of the Foucault's methodological notion of biopolitics. The teacher who participates in the research, seeking continuous training, is challenged by the logic of performance, feeling responsible for their training.

Keywords: Continuing Education; Specialized Educational Service; Maximum capacity; Subjectivation.
\end{abstract}

\section{Introdução}

A inclusão escolar é uma premissa que vem pautando a educação contemporânea, com discussões acadêmicas acerca da formação continuada para o atendimento educacional especializado (AEE) que vêm se ampliando, sobretudo pela via dos movimentos em prol da inclusão e pela legislação. Isso coaduna com um imperativo de que o acento mercadológico perpassa também o campo educacional, o qual permeia as relações sociais na atualidade. Essa

\footnotetext{
${ }^{1}$ Universidade do Vale do Rio dos Sinos (Unisinos), São Leopoldo/RS, daiana_bs@hotmail.com.

${ }^{2}$ Universidade Estadual do Rio Grande do Sul (Uergs), Osório/RS, helena-sardagna@uergs.edu.br.
} 
perspectiva pode ser observada na discussão de trabalhos acadêmicos nos últimos anos, mais precisamente entre 2010 e 2017.

Na composição de um mapeamento a respeito dos contornos acadêmicos da temática pesquisada, apresentamos uma revisão bibliográfica dos artigos que tratam especificamente da formação docente no atendimento educacional especializado. Ferreira $(2002$, p.1) aponta para o número significativo, nas últimas duas décadas, de pesquisas conhecidas e denominadas como estado da arte ou estado do conhecimento. Nesse sentido, tais pesquisas, segundo a autora, vêm tentando dar conta do levantamento dos aspectos pedagógicos e das dimensões sociais que vêm sendo destacados e privilegiados em diferentes épocas e lugares. Dada a importância desses estudos, salientamos que o exercício empreendido neste trabalho não se configura como um estado da arte, mas como um movimento investigativo, buscando observar por onde transitam as problematizações de formação docente no AEE atualmente.

Por ora, priorizamos a busca por trabalhos do banco de dados do Google Acadêmico, por ele conter um número expressivo de trabalhos referentes à formação continuada e o $A E E$, elencando aqueles que contemplassem como descritores no título as palavras "atendimento educacional especializado" e pelo menos uma entre as palavras "formação" e "docente". Para tanto, 22 artigos foram tabulados e sistematizados, por meio de uma planilha de categorização que se deteve a organizar e descrever os seguintes dados: título, ano de publicação e local, resumo, metodologia de pesquisa e síntese de resultados. Além disso, realizamos uma busca complementar na Biblioteca Digital Brasileira de Teses e Dissertações (BDTD), com os descritores "atendimento educacional especializado" e "formação" no título. Assim, foram mapeados seis trabalhos, entre eles três dissertações e três teses.

Quanto à análise, podemos evidenciar alguns movimentos interrogativos nos resumos dos artigos: o movimento com o intuito de mapear, conhecer e problematizar a política, bem como a sua implementação, como a análise das propostas de formação continuada ao AEE em consonância com as políticas, estratégias e táticas dos pesquisadores que agregam esse levantamento (BRIDI, 2011; PLETSCH, 2012; SILUK; PAVÃO, 2012; SILVA; BRUNO, 2016; NOZU; BRUNO, 2013; KAPITANGO-A-SAMBA; HEINZEEN, 2014; MARINHO, 2014; OSTI, 2014; ARAÚJO; FUMES, 2015; FELICIO; FANTACINI; TOREZAN, 2016; QUEIROZ, 2017; VINENTE; OLIVEIRA, 2017); o movimento de problematizar e conhecer concepções, representações e discursos referentes à 
formação docente (FANTACINI; DIAS, 2014; SILVA; SOUZA; BUIATT, 2014; NOZU; BRUNO, 2013; GONÇALVES, 2016; LIMA; GAMA, 2019); e o movimento na via de conhecer e identificar o professor do AEE e a sua respectiva formação (CAPELLINI et al., 2014; CALDAS, 2015; PERTILE; ROSSETTO, 2015; ROSSETTO, 2015; LUZ; DINIZ; LAFONTAINE, 2016; PAIXÃO, 2016; RABELO, 2016).

Nesse movimento, pudemos visualizar a superfície de problematizações referentes à temática da formação continuada no $\mathrm{AEE}$, e que servem de base para o pensamento analítico proposto nesta escrita. Em linhas gerais, evidenciou-se o apontamento de maior parte dos estudos para a necessidade premente de ampliação dos espaços de formação continuada, tendo a escola como lócus fundamental nesse processo. Provocadas por essas discussões, propomonos a realizar um exercício analítico por meio de um olhar, o qual compreende a contemporaneidade como "[...] uma singular relação com o próprio tempo, que adere a este e, ao mesmo tempo, dele toma distâncias" (AGAMBEN, 2009, p.59).

Parte-se da noção de que a racionalidade neoliberal institui uma série de práticas que obedecem a uma imposição da lógica de mercado a todas as esferas sociais, que penetra no espaço educacional. Problematizar a formação docente continuada fora desse contexto parecenos inviável contemporaneamente, pois seria negarmos a ação subjetiva ou "os modos de subjetivação" (CASTRO, 2016) que tal racionalidade implica. Logo, buscamos compreender as implicações da estratégia de formação continuada no AEE e no campo abrangido por esta pesquisa. Em outras palavras, interessa-nos problematizar: quais as implicações da estratégia de formação continuada no atendimento educacional especializado no contexto pesquisado?

Como sustentação teórica metodológica, é pertinente a teorização foucaultiana da noção de biopolítica analisada por Foucault (2008a). Nesse sentido, as regulamentações são criadas com base nos fenômenos da população, aqui entendida como "um conjunto de seres vivos e coexistentes, que apresentam características biológicas e patológicas específicas" (FOUCAULT, 2008b, p.494). A biopolítica é marcada por uma mudança de tônica nas práticas, na medida em que, depois da anátomo-política do corpo humano, instaurada no decorrer do século XVIII, “vemos aparecer, no fim do mesmo século, algo que já não é uma anátomo-política do corpo humano, mas [...] uma 'biopolítica' da espécie humana" (FOUCAULT, 1999, p.289). Assim, utilizamos a noção de biopolítica ora como uma ferramenta analítica, ora como teorização do contexto da pesquisa. 
O movimento empírico sustentou-se em quatro entrevistas semiestruturadas realizadas com professores que trabalham no AEE, em média há nove anos, nas cidades de Torres, Arroio do Sal, Tramandaí e Palmares do Sul, no Rio Grande do Sul. Por meio de um roteiro orientador, a partir de uma lista de tópicos previamente estabelecidos (HAGUETTE, 1995, p.86), as entrevistas foram gravadas e posteriormente transcritas. Estas foram analisadas com o propósito de elencar narrativas em comum, realizando um cruzamento e destacando as recorrências expressas nessas narrativas. Entendendo as entrevistas como um "emaranhado de significados", o que está latente nelas são visões de mundo e jogos de poder, assim como representações que instigam o entrevistado a falar de si e do que o perpassa enquanto sujeito (SILVEIRA, 2002, p.86).

Essas entrevistas são parte constante do banco de dados do Grupo de Pesquisa (a ser identificado após a avaliação) ${ }^{3}$, que se detém na investigação de processos inclusivos e de temáticas que permeiam o AEE como um todo, ancorado em um referencial que assume um caráter de invenção de realidades, colocando tais verdades sob suspeita.

Para compor o exercício analítico, realizamos um breve retrospecto histórico legal para compreendermos o que possibilitou a emergência da formação continuada como uma prática reguladora. Pontuamos algumas políticas referentes à formação docente, considerando que a legislação é uma interface da política e, portanto, da biopolítica - não alheias às práticas próprias de um contexto neoliberal.

Cumpre reiterar que os dados possibilitaram a problematização da emergência do que chamamos nesta escrita de sujeito docente da maximum capacity. Este é entendido como o sujeito que busca a sua máxima capacitação como uma forma de complementação à sua formação individual, de modo que se sinta endividado. Assim, está em constante busca por mais espaço de qualificação e formação, como uma espécie de "dívida social" a ser paga por determinados comportamentos, assumindo os riscos de tal empreendimento. Compreende-se esse sujeito como quem anseia o máximo desempenho, inspirado em Dardot e Laval (2016), que problematizam a emergência do sujeito do máximo desempenho, ou seja, uma figura subjetiva que teve como esteio para a sua emergência as políticas neoliberais que perpassam pela formação continuada.

\footnotetext{
${ }^{3}$ Grupo de Pesquisa a ser informado após a avaliação, cadastrado no Diretório de Grupos de Pesquisa do CNPq, existente desde o ano de 2014.
}

Periódico Horizontes - USF - Itatiba, SP - Brasil - e020021 
A subjetivação na condução do trabalho de si - e da constituição enquanto sujeito - é atravessada por tantas outras subjetividades, como o endividado, o mediatizado, o securitizado (NEGRI; HARDT, 2014), o sujeito do máximo desempenho (DARDOT; LAVAL, 2016), ou todas aquelas "fabricadas" (LAZZARATO, 2011) dentro da racionalidade neoliberal. O estudo da revisão das pesquisas e da análise de dados a partir de entrevistas com os participantes, que marcam o acento na busca por formação permanente, levam-nos a evidenciar a subjetivação pelo endividamento.

\section{Formação, política e legislação: a subjetivação pelo endividamento}

Para compreendermos o campo atual de formação continuada, entendendo-o como um processo datado, faz-se necessário trazer fragmentos históricos e legais, buscando marcas da sua emergência. Foucault (1995, p.232) salienta que necessitamos de uma consciência da situação presente. Ao tecer tal investimento, salientamos o seu caráter exploratório na via de um embasamento para a compreensão das tramas neoliberais que enredam os sujeitos docentes na contemporaneidade, na intenção de contextualizar algumas práticas e políticas de formação continuada que se exercem dentro de uma governamentalidade política.

\footnotetext{
Essa governamentalidade política é marcada, então, por um conjunto de ações articuladas numa maquinaria de poder, que consiste em exercer um controle sobre os indivíduos, através do trabalho sobre as populações nas quais esses indivíduos estão inseridos, de modo que eles se acreditem cidadãos livres, participativos e peças centrais no jogo democrático (GALLO, 2013, p.204).
}

Cabe mencionar que nos afastamos do propósito de apresentar "a história" da formação continuada, buscando em vez disso pontuar alguns fragmentos importantes, a nosso ver, para as reflexões abarcadas nesta escrita. Consideramos aspectos que permitem compreender as condições políticas que tornaram possível a emergência da formação continuada como um conjunto de práticas tomadas como necessárias, no contexto da contemporaneidade.

Foucault (2008b) aponta para processos que ocorrem desde a sociedade da soberania até a sociedade de normalização. "A normalização disciplinar consiste em primeiro colocar em um modelo, um modelo ótimo que é construído em função de certo resultado" (FOUCAULT, 2008b, 
p.75). Tanto uma como a outra se caracterizam pelas relações de poder disciplinar e, ao constituírem o desenvolvimento do biopoder, tornam-se eixos dele. Em outros termos, não nos referimos à passagem ou transição de uma sociedade para outra; o que queremos destacar é a mudança de ênfases nas relações de poder. "A soberania se exerce nos limites de um território, a disciplina se exerce sobre o corpo dos indivíduos e, por fim, a segurança se exerce sobre o conjunto de uma população" (FOUCAULT, 2008b, p.15-16).

O que as "identifica" são os mecanismos de ação do poder ${ }^{4}$, as tecnologias disciplinares - sociedade disciplinar - e as tecnologias regulamentadoras - sociedade de controle. Nesse sentido, o controle até então exercido sobre o indivíduo e o seu corpo tomam novas formas, no marco geral de uma "biopolítica: esta tende a tratar a população como um conjunto de seres vivos e coexistentes, que apresentam características biológicas e patológicas específicas" (FOUCAULT, 2008b, p.494). É nessa mudança, a partir das relações de poder das sociedades disciplinares para as sociedades de controle, que notamos condições que tornaram possível a formação continuada. Na compreensão das políticas públicas enquanto práticas de promoção da vida, com a ação da biopolítica direcionada às massas, enquanto práticas de promoção da vida, "a formação continuada pareceu-me indicar um forte sinal da emergência de controles reguladores no âmbito educacional" (SANTOS, 2006, p.66).

Enquanto campo de conhecimento, a formação de professores teve como marco no Brasil a década de 1930, com a criação do Ministério da Educação e a produção de documentos importantes, como o Manifesto dos Pioneiros, construído por Anísio Teixeira e outros integrantes do movimento Escola Nova. Esses documentos elencavam reivindicações quanto à formação e à valorização dos professores.

Na mesma década, foram criados os Institutos de Educação, inspirados nos ideais da Escola Nova, tendo a sua base fundamentada na pesquisa e no ensino, com destaque às propostas de Anísio Teixeira e Fernando de Azevedo, que propuseram uma das primeiras escolas de professores. Tais experiências serviram de alicerce para a criação de diversos cursos de formação de professores em todo o país, destacando-se a Faculdade Nacional de Filosofia da

\footnotetext{
${ }^{4}$ São relações de poder que "supõem condições históricas de emergência, complexas, e implicam múltiplas consequências, inclusive fora do que a análise filosófica identifica tradicionalmente como o campo do poder" (REVEL, 2011, p.120). O poder desenvolve-se por meio de ações microscópicas de uns sobre os outros.
} 
Universidade do Brasil, no Rio de Janeiro, criada conforme o Decreto-Lei no 1.190, de 4 de abril de 1939, perdurando até o período de governo militar (BRASIL, 1939).

Como documentos regulamentadores da formação docente, apontamos a Lei no 5.692, de 11 de agosto de 1971, que fixa as Diretrizes e Bases para o ensino de $1^{\circ}$ e 20 graus e dá outras providências (BRASIL, 1971), e a Constituição Federal de 1988, que efetivou uma política pública de acesso à educação universal. Este documento dispõe, em seus Artigos 205으, 206으 e 208으, sobre a premissa da educação como um direito de todos, a igualdade de condições visando à permanência do aluno na escola, assim como a indicação da oferta do atendimento educacional especializado preferencialmente na rede regular de ensino (BRASIL, 1988).

Em decorrência desse cenário, a Lei de Diretrizes e Bases da Educação Nacional (LDBEN), no 9394 de 20 de dezembro de 1996, contempla, no Art. 62:

[...] formação de docentes para atuar na educação básica far-se-á em nível superior, em curso de licenciatura plena, admitida, como formação mínima para o exercício do magistério na educação infantil e nos cinco primeiros anos do ensino fundamental, a oferecida em nível médio, na modalidade normal (BRASIL, 1996).

Além de definir como se dará a formação de professores, a LDBEN dispõe sobre a responsabilidade do Estado com tal formação, preconizando, no parágrafo §1ำ, que "A União, o Distrito Federal, os Estados e os Municípios, em regime de colaboração, deverão promover a formação inicial, a continuada e a capacitação dos profissionais de magistério". Assim, estabelece a prerrogativa legal do compromisso e da responsabilidade das instâncias

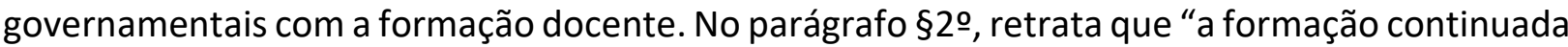
e a capacitação dos profissionais de magistério poderão utilizar recursos e tecnologias de educação à distância" (BRASIL, 1996). Nesse sentido, ratifica meios de atingir o maior número de indivíduos com o mínimo esforço do Estado, gerando dessa forma uma economia política.

Ainda dispõe, no Artigo 59, inciso III, que os sistemas de ensino deverão assegurar aos educandos com deficiência, transtornos globais do desenvolvimento e altas habilidades ou superdotação, no que tange à formação docente, professores com especialização adequada em nível superior para o AEE, bem como professores do ensino regular capacitados à inclusão desses educandos nas classes comuns. Nesse contexto, a LDBEN (BRASIL, 1996) delineia o cenário da 
formação docente, marcando como esta deve ser contemplada e expandida, quando estabelece os parâmetros a serem atendidos por esses profissionais. Isso vale não somente ao âmbito da qualificação inicial, mas também - e possivelmente com muito mais força - no âmbito da educação continuada, em função da demanda, por parte do mercado em curto espaço de tempo, de profissionais que atendam aos requisitos estabelecidos pelo sistema educacional em um nível macropolítico, de leis, decretos e diretrizes.

No âmbito da legislação, a capacitação como elemento crucial à formação docente e como elemento acionador da formação continuada passa a se estabelecer como um imperativo no rol da racionalidade liberal. A Resolução CNE/CBE no 2, de 11 de setembro de 2001, que institui as Diretrizes Nacionais para a Educação Especial na Educação Básica, dispõe sobre a organização das escolas de ensino regular quanto às suas classes comuns, que, entre outros aspectos, deve prover "professores de classes comuns e de educação especial, capacitados e especializados" (BRASIL, 2001, p.72).

A Lei no 12.014, de 6 de agosto de 2009, altera o Artigo 61 da LDBEN, no inciso III, definindo "a associação entre teorias e práticas mediante estágios supervisionados e capacitação em serviço" como um fundamento da formação de professores. Aqui podemos evidenciar a capacitação como um dos elementos fundamentais no se refere à formação continuada (BRASIL, 2009c).

Nesse contexto, em relação à educação especial, um dos documentos orientadores do AEE - a Resolução no 4, de 2 de outubro de 2009, que institui Diretrizes Operacionais para o Atendimento Educacional Especializado na Educação Básica, modalidade Educação Especial — salienta que o projeto político pedagógico (PPP) da escola deve institucionalizar o AEE, prevendo na sua organização, no inciso VII: "redes de apoio no âmbito da atuação profissional, da formação, do desenvolvimento da pesquisa, do acesso a recursos, serviços e equipamentos" (BRASIL, 2009b, p.2). No Artigo 12 consta a formação necessária para atuação no AEE: o professor deve ter "formação inicial que o habilite para o exercício da docência e formação específica para a Educação Especial” (BRASIL, 2009b, p.2). Com a legislação específica à implementação do AEE, pontuando as suas condições de operacionalização, o Estado se vê diante de uma demanda muito grande por professores que atendam às especificidades dessa formação exigida em lei. Isso impulsiona a promoção e o incentiva à capacitação, dentro do contexto de uma governamentalidade política sustentada nos pilares da economia política. 
Como consequência dessas prerrogativas legais, a Resolução no 04, de 13 de julho de 2010 (Diretrizes Curriculares Nacionais Gerais para a Educação Básica), no Artigo 29, define a educação especial como uma modalidade de ensino transversal a todos os níveis e parte integrante da educação regular, devendo ser prevista no projeto político pedagógico da unidade escolar. Ainda no parágrafo §3으, destaca orientações fundamentais para os sistemas de ensino, com a finalidade de organização dessa modalidade, abordando como premissa, no inciso III, "a formação de professores para o AEE e para o desenvolvimento de práticas educacionais inclusivas" (BRASIL, 2013b, p.72).

Reforça, no Artigo 57, a importância da valorização da educação e estabelece, nos parágrafos 10 e 20 , respectivamente, que a valorização do profissional da educação deve vincular-se obrigatoriamente à qualidade da escola. Essa valorização também se relaciona à exigência de propostas de formação inicial e continuada. Outro aspecto é a necessidade de a qualificação dos profissionais de educação se dar nos programas de formação inicial e continuada, conforme incisos I, II, III e IV, no sentido de desenvolver habilidades de interpretar e reconstruir o conhecimento de forma coletiva, trabalhar cooperativamente, compreender, interpretar e aplicar a linguagem e os instrumentos produzidos ao longo da evolução tecnológica e econômica, assim como o desenvolvimento de competências para a "integração com a comunidade e para o relacionamento com as famílias" (BRASIL, 2013b, p.78).

A Lei no 12.796, de 4 abril de 2013, altera a Lei no 9.394, de 20 de dezembro de 1996 (LDBEN), para dispor sobre a formação dos profissionais da educação. No Artigo 62A está prevista a "formação continuada para os profissionais a que se refere o caput, no local de trabalho ou em instituições de educação básica e superior, incluindo cursos de educação profissional, cursos superiores de graduação plena ou tecnológicos e de pós-graduação" (BRASIL, 2013a)

As diretrizes para a formação de professores mais recentes na Resolução no 02 de 1ㅇ de julho de 2015, apresentam no Artigo 3ํ, inciso X, que a formação continuada é "componente essencial da profissionalização inspirado nos diferentes saberes e na experiência docente, integrando-a ao cotidiano da instituição educativa, bem como ao projeto pedagógico da instituição de educação básica" (BRASIL, 2015, p.5).

Essas políticas públicas podem ser relacionadas a práticas de um contexto neoliberal, como uma arte que seduz os sujeitos da sociedade, por meio de certas metanarrativas 
constituidoras de necessidades coadunadas a esse contexto. Se no governo soberano a sociedade disciplinar (FOUCAULT, 2008b) produziu o homem confinado, no neoliberalismo contemporâneo, com a transição da ênfase para o biopoder, a sociedade de controle produziu novas subjetividades - ou figuras subjetivas.

Nessa perspectiva, a sociedade de controle transfere a ênfase na disciplina para a ênfase no controle, ou seja, "enquanto a disciplina moderna funciona para produzir corpos dóceis, o controle pós-moderno funciona para produzir corpos flexíveis" (VEIGA-NETO, 2008, p.37). Os corpos produzidos na lógica do controle são corpos flexíveis, que se adaptam facilmente às mudanças do meio e que não estão submetidos a paredes como os corpos dóceis, e sim a redes de pessoas, instituições, políticas que os enredam e trabalham no sentido da constituição de novas subjetividades.

Michel Foucault, na aula de 28 de março de 1979, publicada na obra Nascimento da Biopolítica (2008a), desenvolve o conceito de homo oeconomicus, o qual definiu como o "sujeito ou objeto do laissez-faire". Ele ressalta que se trata daquele que é "eminentemente governável":

O homo oeconomicus, é aquele que obedece ao seu interesse, é aquele cujo interesse, é qual que, espontaneamente, vai convergir com o interesse dos outros. O homo oeconomicus é, do ponto de vista de uma teoria do governo, aquele em que não se deve mexer. Deixa-se o homo oeconomicus fazer (FOUCAULT, 2008a, p.369).

Nesse sentido, o homo oeconomicus torna-se um parceiro importantíssimo de um governo da lógica do laissez-faire. Este aceita a realidade e responde de forma sistemática às modificações do meio no qual se encontra. Nesse contexto, o homo oeconomicus é o elemento básico de uma "[...] nova arte de governar que começou a ser formulada, pensada e desenhada mais ou menos em meados do século XVIII" (FOUCAULT, 2008a, p.39). Em essência, o homo oeconomicus é uma condição de possibilidade para que a arte do governar liberal possa emergir, estabelecendo-se como um "[...] sujeito que permitia justamente que uma arte de governar se regulasse de acordo com o princípio da economia" (FOUCAULT, 2008a, p.370). Nesse sentido, "o homo oeconomicus se vê, portanto, situado no que poderíamos chamar de duplo involuntário: o involuntário dos acidentes que lhe sucedem e o involuntário do ganho que ele produz para os outros sem que o tenha pretendido" (FOUCAULT, 2008a, p.378). 
O homo oeconomicus corresponde a uma mecânica que o coloca como um sujeito de interesse individual, dentro de um sistema geral, dentro dessa totalidade que lhe escapa e que, ao mesmo tempo, fomenta essa racionalidade de escolhas individuais. O bem coletivo não deve ser pretendido, visado, almejado - não pode ser calculado.

\section{Formação continuada para o AEE: atravessamentos neoliberais}

Dada a complexidade do conceito de neoliberalismo, destacamos a definição de Shamir (2008 apud BALL, 2014) que compreende como um conjunto complexo, muitas vezes incoerente e até mesmo contraditório de práticas que são organizadas em torno de certa imaginação de mercado. Reconhece tanto as relações materiais como as sociais hibridadas nesse processo, apontando para duas concepções de neoliberalismo. A primeira tem foco neomarxista sobre a "economização da vida social" e a criação de novas oportunidades de lucro; a segunda "[...] vai dispor das teorizações foucaultianas de governamentalidade e subjetivação que produzem empreendedores dispostos, auto-governamentáveis" (BALL, 2014, p.26). Compreendendo o neoliberalismo na junção dessas duas concepções, pode-se inferir que a segunda concepção tem maior aproximação às problematizações descritas neste artigo.

Segundo Dardot e Laval (2016), em A Nova Razão do Mundo, o neoliberalismo não se reduz a uma política econômica e cultural, e também não se configura como uma volta ao passado. Seria, nessa concepção, uma racionalidade global de políticas que transformam o Estado - as relações culturais e as interpessoais - como uma lógica normativa universal que se divide em dois polos: de um lado, a norma transversal difusa da concorrência; de outro, a imposição do modelo empresarial. Essa nova razão denota uma criação de políticas deliberadas da criação de situações de mercado e modelos de concorrência.

Dardot e Laval (2016) tensionam o entendimento de que o neoliberalismo é a expansão do mercado em detrimento do Estado, ratificando assim que é mais do que isso: é o próprio Estado que se transforma, por meio das normas em um neoliberalismo. Um Estado gerenciador seria como uma empresa, agindo e sendo regido pelas lógicas de mercado, fundamentando-se pelo princípio empresarial. Tal movimento faz da competitividade um princípio constitucional.

Esse princípio constitucional, como nomeiam os autores, embasa o fomento de políticas 
neoliberais de formação continuada para o atendimento educacional especializado. Entendendo o contexto dessas políticas, operando na constituição de novas figuras subjetivas contemporâneas de docentes, voltamos o nosso olhar para tais subjetividades. Nesse cenário, a política atual de educação especial na perspectiva da educação inclusiva prevê o AEE como apoio pedagógico para a inclusão. A operacionalização desse serviço de apoio está prevista no Parecer 13 de 2009, que, entre as prioridades, estabelece orientações para a elaboração de plano do AEE e competências do professor especialista; inclusão do AEE no projeto pedagógico da escola da rede regular de ensino; condições para a realização do AEE em centros; atribuições do professor que realiza o AEE; e formação do professor para atuar na Educação Especial e no AEE (BRASIL, 2009a).

Apesar de a política estar em vigência há uma década, nota-se que no contexto pesquisado as práticas formativas deixam lacunas e não atendem às expectativas.

\footnotetext{
Não sei onde está havendo o erro sobre a inclusão, sei que todos têm direito a escola, mas, estão colocando crianças na inclusão sem o mínimo de conhecimento pedagógico, precisando de uma estimulação, ou seja uma preparação inicial. Simplesmente estão colocando numa sala de aula e o professor que se vire. Aí vem a pergunta? Mas tem um(a) auxiliar? Sim, tem, mas sem capacitação também (ENTREVISTADA 1).
}

O AEE consolidou-se enquanto um imperativo por meio da legislação vigente a partir de 2009. A política atual de educação especial na perspectiva da educação inclusiva prevê o atendimento educacional especializado como apoio pedagógico para a inclusão, na Resolução 4/2009, no Art. 50, definindo que "O AEE é realizado, prioritariamente, na sala de recursos multifuncionais da própria escola ou em outra escola de ensino regular, no turno inverso da escolarização, não sendo substitutivo às classes comuns [...]" (BRASIL, 2009b). Nessa perspectiva, emerge a necessidade de profissionais capacitados para atender essa demanda preconizada na legislação específica.

\section{A subjetivação na lógica da maximização de resultados: maximum capacity}

Na literatura contemporânea, estudos apontam para a emergência de novas figuras subjetivas, que encontram na expansão e na abrangência da racionalidade neoliberal uma 
condição de possibilidade para emergirem (LAZZARATO, 2011; NEGRI; HARDT, 2014).

Segundo Bauman e Bordoni (2016, p.15), vivemos em um constante estado de crise, com a qual temos de nos habituar a conviver. Quando uma crise acaba, outra entra em cena e toma o seu lugar - podendo ser ainda a mesma crise, a qual foi se alimentando, transformando-se e regenerando-se como uma "entidade teratogênica monstruosa". No interior da regeneração da crise neoliberal, Negri e Hardt (2014) problematizam a emergência de três figuras subjetivas: o endividado, o mediatizado e o securitizado.

O triunfo do neoliberalismo e sua crise mudaram os termos da vida econômica e política, mas também operaram uma transformação social e antropológica, fabricando novas figuras de subjetividade. [...] A hegemonia das finanças e dos bancos produziram o endividado. O controle das informações e das redes de comunicação criaram o mediatizado. O regime de segurança e o estado generalizado de exceção construíram a figura oprimida pelo medo e sequiosa de proteção: o securitizado (NEGRI; HARDT, 2014, p.21).

Nesse sentido, Lazzarato (2011) aponta e reforça que as estratégias na racionalidade neoliberal culminaram na emergência do homem endividado e transformaram os direitos sociais (educação, saúde, segurança, assistência etc.) em dívidas a serem pagas pelos indivíduos, mediante determinados comportamentos, ou seja, a transformação dos direitos sociais em dívidas sociais.

O poder da dívida não se representa e não se exerce nem pela repressão, nem pela ideologia: o devedor é "livre", mas suas ações, seus comportamentos devem ser realizados dentro do quadro definido pela dívida que ele contraiu. Isso se aplica tanto para os indivíduos quanto para uma população ou um grupo social. Você é livre na medida da extensão de onde você assume o estilo de vida (consumo, emprego, despesas sociais, impostos etc.) compatível com o reembolso (LAZZARATO, 2011, p.28).

Foucault (2008a), em sua aula de 14 de março de 1979, também se deteve a problematizar subjetividades suscitadas pela racionalidade neoliberal, ao descrever o homo oeconomicus como parceiro de uma nova razão governamental tal como se formula no século XVIII. O sujeito, nesse sentido, é auto governável e se molda facilmente.

Dardot e Laval (2016) apontam para a figura subjetiva do sujeito do máximo desempenho 
que está no jogo neoliberal de competição. Essa concorrência, segundo os autores, favorece os mais aptos, e o "efeito" disciplinador da concorrência atua como estímulo ao bom desempenho, operando pela subjetividade na constituição do sujeito do bom desempenho. "A produção da subjetividade é a produção mais importante na economia contemporânea" (LAZZARATO, 2011, p.30). A subjetividade contemporânea seria o coração da racionalidade neoliberal.

Essas subjetividades do homem endividado, do homem mediatizado, do homem securitizado, do sujeito do máximo desempenho, estão voltadas à produção do investimento em si mesmo, a lógica de gerir-se segundo um ideário de mercado - mais do que isso, à responsabilização de assumir riscos.

Nesse sentido, a racionalidade neoliberal produz o sujeito que precisa ordenar os meios de governar-se, para que ele se conduza realmente como uma entidade em competição. Por isso, deve maximizar os seus resultados, expondo-se a riscos e assumindo a inteira responsabilidade por eventuais fracassos (DARDOT; LAVAL, 2016, p.328).

$\mathrm{Na}$ análise das narrativas expressas nas entrevistas, identificamos um movimento dos docentes em capacitar-se constantemente, autogerindo-se e, por vezes, até mesmo assumindo a responsabilidade e os riscos em relação a esse movimento, permeados por um sentimento de culpa a respeito da sua própria formação.

\footnotetext{
A dívida segrega uma "moral" própria, diferente e complementar daquela do "trabalho". A dupla "esforço-recompensa" da ideologia do trabalho é substituída pela moral da promessa (de honrar sua dívida) e da culpa (de tê-la contraído). Como nos lembrou Nietzsche, o conceito de "Schuld" (culpa), conceito fundamental da moralidade, remonta ao conceito muito material de "Schulden" (dívidas) (LAZZARATO, 2011, p.28).
}

As narrativas também apontam para a possibilidade de emergência e constituição da figura subjetiva, que, no contexto da pesquisa, intitulamos como o sujeito da maximum capacity no âmbito da problematização. Esse sujeito é atravessado pelas figuras subjetivas do endividado, do mediatizado, do securitizado e do sujeito do máximo desempenho, assim como pela figura do homo oeconomicus.

Na verdade, como profissional nomeada em área há 15 anos, já estou habilitada há mais de 20 anos, e sempre atualizada, ora por oportunidade do próprio 
Governo Federal com o advento da Inclusão, ora por próprio investimento financeiro, pois acredito que faz parte de um bom profissional garantir sua atualização independente da forma, seja gratuita ou financiada pelo próprio salário (ENTREVISTADA 2).

No dizer da professora, evidenciamos a preocupação com a sua própria capacitação, a ponto de ela pretender assumir para si os custos de tal investimento - fato observado quando se refere ao esforço que deve ser empreendido por ela na sua capacitação. "Você vive se endividando, e vive sob o peso de sua responsabilidade em relação à dívida" (NEGRI; HARDT, 2014, p.22). Sob a responsabilidade de capacitar-se continuadamente, o professor vive tendo a sua subjetividade constituída na base da dívida. Nesse sentido, podemos compreender o sujeito da maximum capacity como aquele que se sente em permanente dívida quanto à sua própria formação.

Os indivíduos assumem os riscos do trabalho de $\mathrm{si}^{5}$, enquanto um sujeito empresa, que faz a sua autogestão. Como em outras esferas sociais, esse mecanismo de individualização e responsabilização está presente no meio educacional, modificando as relações sociais e interpessoais. Em outras palavras, o professor necessita de formação constante. O mecanismo da dívida social se estabelece no âmbito da liberdade individual: somos livres diante das escolhas, mas, em contrapartida, contraímos dívidas a serem pagas pelos nossos comportamentos, por meio de uma subjetividade que nos constitui enquanto sujeitos endividados.

A dívida, enquanto é base da subjetividade do sujeito do maximum capacity, disciplina-o e conduz a sua conduta na via do pagamento da dívida social que adquire, ao ocupar o lugar de professor do AEE. O efeito da dívida conduz o sujeito na via da capacitação contínua e da subjetividade da responsabilidade e da culpa.

Fiz um curso de especialização subsidiado pelo MEC, porém não houve mais atualização. E os municípios não possuem verbas, e/ou muitas vezes não percebem a importância da capacitação de professores nesta área, deixando tudo nas mãos do professor do AEE. Sinto que deveria me capacitar mais, participar de mais cursos (ENTREVISTADA 3).

\footnotetext{
${ }^{5} \mathrm{O}$ cuidado de si adotado neste trabalho está relacionado ao contexto neoliberal e, como tal está a serviço de uma racionalidade neoliberal. Portanto, difere-se do cuidado de si, problematizado e compreendido no contexto da Grécia antiga.
}

Periódico Horizontes - USF - Itatiba, SP - Brasil - e020021 
O sujeito da maximum capacity se sente responsável pela sua própria capacitação e culpado pelas possíveis dificuldades que ela impõe. Segundo Negri e Hardt (2014), a culpa para o endividado passa a ser uma forma de vida, uma disciplina que implica um trabalho de si, e é indissociável da produção de uma subjetividade específica.

O usuário transformado em um devedor, em contraste com o que se passa nos mercados financeiros, não deve reembolsar em dinheiro local, mas em comportamentos, atitudes, maneiras de agir, projetos, engajamentos subjetivos, tempo dedicado a procura de emprego, tempo utilizado para se formar de acordo com os critérios ditados pelo mercado e pela empresa, etc. (LAZZARATO, 2011, p.81).

Esses comportamentos se expressam nas mais variadas formas, mas sempre no sentido de assumir os riscos de pensar-se enquanto uma empresa. Logo, o sujeito da maximum capacity é atravessado pela subjetividade do homem mediatizado, não no sentido de alienação, mas diante da massa das redes de comunicação. Portanto, é um sujeito que cada vez menos consegue dissociar trabalho e vida. "Vejo em tudo isso à importância de estarmos sempre atualizados, habilitados e munidos do assunto inclusão" (ENTREVISTADA 3). As redes de comunicação como Facebook, WhatsApp, Twitter, muito mais do que propiciarem uma conexão superficial e veloz, "acompanham o indivíduo", cercam-no e o enredam. Nesse caso específico, o professor se constitui subjetivamente em um sujeito mediatizado. "Quase toda semana somos informadas de cursos de capacitação, as gurias postam no grupo do WhatsApp. O problema é o custo, o deslocamento, mas, mesmo assim, algumas sempre fazem" (ENTREVISTADA 3). Em resumo, a informação é mediatizada e enreda o sujeito professor mesmo distante do espaço territorial da escola. O sujeito mediatizado é alcançado e interpelado pelas redes de informações que o capturam.

Nesse contexto, o sujeito da maximum capacity também é atravessado pela figura do sujeito securitizado (NEGRI; HARDT, 2014), bem como pela figura do sujeito do máximo desempenho (DARDOT; LAVAL, 2016). Ao mesmo tempo em que o professor entrega a sua liberdade em prol de um sentimento de maior segurança, ele se esforça e deseja gozar de reconhecimento e de bom desempenho. Esses dois elementos o impulsionam a desejar e a realizar um trabalho de si, no sentido de capacitar-se continuamente, num processo que não se esgota em si mesmo. 
Mensalmente são realizados encontros com os profissionais das salas de recursos e [...], professores titulares e auxiliares de turmas com alunos com deficiência. Entretanto, percebe-se que a frequência de tais profissionais muitas vezes deixa a desejar. Infelizmente, muitas vezes as oportunidades de capacitação não são bem aproveitadas por tais professores, evidenciando que ainda é necessário que se sensibilize os professores para a inclusão, o que dificulta o trabalho do AEE (ENTREVISTADA 4).

Esse trabalho de si - essa subjetividade que constitui o sujeito da maximum capacity é ao mesmo tempo um trabalho de condução da conduta do outro enquanto se conduz a própria, ou seja, uma constante vigia de si e do outro. O professor deseja capacitar-se não porque é forçado no sentido físico e/ou psicológico a tal, mas porque deseja, porque acredita que um bom profissional do AEE é aquele que se capacita constantemente, responde à mediatização cotidiana da massa de informações e precisa sentir-se seguro. Assim, atinge o máximo desempenho e goza dos benefícios associados a tal resultado. "Acredito que um bom profissional é aquele que busca o aperfeiçoamento constante, não vejo outra saída, não tem como escapar. Ou nos capacitamos, ou não conseguimos dar conta de tanta diversidade" (ENTREVISTADA 4). Nessa lógica, o sujeito entende que o outro também deve adotar tais comportamentos e, por isso, exerce um processo de vigília constante, o que ocasiona uma economia política muito bem-vinda ao Estado.

\section{Para não terminar: potências do estudo}

Ao investigar sobre como a estratégia de formação continuada no atendimento educacional especializado opera, por meio do contexto neoliberal, nos indivíduos pesquisados, e quais implicações podem ser evidenciadas, é possível inferir que a formação continuada ao AEE se apresenta e se edifica como uma prática regulamentadora, estabelecendo subjetividades que conduzem os docentes à maximização de esforços, no sentido de estar sempre se capacitando. Essa valorização da formação continuada como uma prática e um movimento "desejável" por parte dos professores tem como uma das condições de possibilidades para a sua emergência a racionalidade neoliberal, que institui a lógica do mercado, estendendo-a a todas as esferas sociais.

As políticas neoliberais de formação continuada germinaram num terreno frutífero, que nos possibilitou o que denominamos sujeito da maximum capacity. Esse sujeito é interpelado e atravessado por tantas outras figuras subjetivas contemporâneas, constituídas na lógica da 
concorrência. Nesse sentido, o professor é subjetivado a gerir-se enquanto uma empresa, e deseja capacitar-se constantemente em busca do desempenho, em uma sociedade de exacerbada valorização do imediato, do fluído, da produção de insegurança.

A estratégia de formação continuada no AEE opera dentro de um contexto neoliberal, possibilitando a emergência do sujeito da maximum capacity. Entende-se que essa emergência é efeito da ação da biopolítica que tem como alvo o conjunto de indivíduos. O sujeito professor é constituído no trabalho de si por meio de uma subjetividade ancorada na responsabilidade e na culpa diante da sua formação enquanto profissional.

Bauman (2001, p.8) descreve a liquefação do mundo contemporâneo, referindo-se aos fluídos que "não fixam o espaço e nem prendem o tempo", na passagem da sociedade moderna à sociedade pós-moderna e/ou contemporânea. Nesse estado pós-moderno enquanto forma de vida, nada mais é sólido nem seguro (no sentido de estável): tudo nos escapa. Nesse sentido, muitas coisas nos escapavam no movimento desta pesquisa. Assim, esperamos que o que nos escapa seja "retido" e problematizado por outros movimentos analíticos.

\section{Referências}

AGAMBEN, G. O que é o contemporâneo? e outros ensaios. Trad. Vinicius N. Honesko. Chapecó: Argos, 2009.

ARAÚJO, L. R; FUMES, N. L. A. formação de professores do atendimento educacional especializado da rede estadual na cidade de Maceió/AL. In: CONGRESSO NACIONAL DE EDUCAÇÃO, 2., 2015, Campina Grande. Anais... Campina Grande: Realize, 2015.

BALL, S. J. Educação global S. A.: novas redes políticas e o imaginário neoliberal. Trad. Janete Bridon. Ponta Grossa: UEPG, 2014.

BAUMAN, Z. Modernidade Líquida. Trad. Plínio Dentzien. Rio de Janeiro: Jorge Zahar, 2001.

BAUMAN, Z.; BORDONI, C. Estado de crise. Trad. Renato Aguiar. Rio de Janeiro: Zahar, 2016.

BRASIL. Decreto-Lei no 1.190, de 4 de abril de 1939. Dá organização à Faculdade Nacional de Filosofia. Diário Oficial da União, 6 de abril de 1939, Seção 1, p.7929. Brasília, 1939. Disponível em: https://www2.camara.leg.br/legin/fed/declei/1930-1939/decreto-lei-1190-4-abril-1939349241-publicacaooriginal-1-pe.html. Acesso em: 14 jul. 2019.

BRASIL. Lei $n$ o 5.692, de 11 de agosto de 1971. Fixa as diretrizes e bases para o ensino de 1 으 e 
2ำ graus, e dá outras providências. Diário Oficial da União, 12 de agosto de 1971. Seção 1, p.6377, Poder Executivo. Brasília, 1971. Disponível em:

https://www2.camara.leg.br/legin/fed/lei/1970-1979/lei-5692-11-agosto-1971-357752publicacaooriginal-1-pl.html. Acesso em: 14 de jul. 2019.

BRASIL. Constituição da República Federativa do Brasil de 5 de outubro de 1988. Brasília: Senado Federal, 1988. Disponível em:

http://www.planalto.gov.br/ccivil_03/constituicao/constituicao.htm. Acesso em: 14 jul. 2019.

BRASIL. Lei no 9.394 de 20 de dezembro de 1996. Estabelece as diretrizes e bases da educação nacional (LDBEN). Poder Executivo. Brasília: Senado Federal, 1996. Disponível em: http://www.planalto.gov.br/ccivil_03/leis/I9394.htm. Acesso em: 14 jul. 2019.

BRASIL. Conselho Nacional de Educação. Câmara de Educação Básica. Resolução CNE/CEB no 2, de 11 de setembro de 2001. Institui Diretrizes Nacionais para a Educação Especial na Educação Básica. Brasília, 2001. Disponível em: http://portal.mec.gov.br/cne/arquivos/pdf/CEB0201.pdf. Acesso em: 30 jul. 2019.

BRASIL. Conselho Nacional de Educação. Câmara de Educação Básica. Parecer no 13, de 3 de junho de 2009. Diretrizes Operacionais para o atendimento educacional especializado na Educação Básica, modalidade Educação Especial. Brasília, 2009a. Disponível em: http://portal.mec.gov.br/dmdocuments/pceb013_09_homolog.pdf. Acesso em: 30 jul. 2019.

BRASIL. Conselho Nacional de Educação. Câmara de Educação Básica. Resolução no 4, de 2 de outubro de 2009. Institui Diretrizes Operacionais para o atendimento educacional especializado na Educação Básica, modalidade Educação Especial. Brasília, 2009b. Disponível em: http://portal.mec.gov.br/dmdocuments/rceb004_09.pdf. Acesso em: 30 jul. 2019.

BRASIL. Lei no 12.014, de 6 de agosto de 2009. Altera o art. 61 da Lei no 9.394, de 20 de dezembro de 1996, com a finalidade de discriminar as categorias de trabalhadores que se devem considerar profissionais da educação. Brasília, 2009c. Disponível em:

http://www.planalto.gov.br/ccivil_03/_ato2007-2010/2009/lei/l12014.htm. Acesso em: 30 jul. 2019.

BRASIL. Conselho Nacional de Educação. Câmara de Educação Básica. Resolução no 4, de 13 de julho de 2010. Define Diretrizes Curriculares Nacionais Gerais para a Educação Básica. Disponível em: http://portal.mec.gov.br/dmdocuments/rceb004_10.pdf. Acesso em: 13 de jul. 2019.

BRASIL. Lei no 12.796, de 4 de abril de 2013. Altera a Lei no 9.394, de 20 de dezembro de 1996, que estabelece as diretrizes e bases da educação nacional, para dispor sobre a formação dos profissionais da educação e dar outras providências. Brasília, 2013a. Disponível em: http://www.planalto.gov.br/ccivil_03/_Ato2011-2014/2013/Lei/L12796.htm. Acesso em: 30 jul. 2019.

BRASIL. Ministério da Educação. Secretaria de Educação Básica. Diretrizes curriculares nacionais 
gerais da educação básica de 2013. Brasília: MEC/SEB/DICEI, 2013b. Disponível em: http://portal.mec.gov.br/docman/julho-2013-pdf/13677-diretrizes-educacao-basica-2013pdf/file. Acesso em: 18 jul. 2019.

BRASIL. Ministério da Educação. Conselho Nacional de Educação. Conselho Pleno. Resolução no2, de 1ㅇ de julho de 2015. Define as Diretrizes Curriculares Nacionais para a formação inicial em nível superior. Disponível em: http://portal.mec.gov.br/docman/agosto-2017-pdf/70431res-cne-cp-002-03072015-pdf/file. Acesso em: 13 jul. 2019.

BRIDI, F. R. S. Formação continuada em educação especial: o atendimento educacional especializado. Poiésis, Rio de Janeiro, v.4, n.7, p.187-199, 2011.

CALDAS, W. K. Tecnologia assistiva e computacional: contribuições para o atendimento educacional especializado e desafios na formação de professores. 2015. 214f. Tese (Doutorado em Educação) - Programa de Pós-Graduação em Educação, Universidade Federal do Espírito Santo, Vitória, 2015.

CAPELLINI, V. L. M. F.; RINALDO, S. C. O.; ZANATA, E. M.; FONSECA, K. A. Atendimento educacional especializado: algumas reflexões a partir da formação continuada realizada pelo observatório de educação especial (ONEESP). In: CONGRESSO NACIONAL DE FORMAÇÃO DE PROFESSORES, 2.; CONGRESSO ESTADUAL PAULISTA SOBRE FORMAÇÃO DE EDUCADORES, 12., 2011, Águas de Lindóia. Anais... Águas de Lindóia: Universidade Estadual Paulista, 2014, p.8911-8923.

CASTRO, E. Vocabulário de Foucault: um percurso pelos seus temas, conceitos e autores. Trad. Ingrid M. Xavier. 2. ed. Belo Horizonte: Autêntica, 2016.

DARDOT, P.; LAVAL, C. A nova razão do mundo: ensaio sobre a sociedade neoliberal. Trad. Mariana Echalar. São Paulo: Biotempo, 2016.

FANTACINI, R. A. F.; DIAS, T. R. S. Alunos com necessidades educacionais especiais em uma rede municipal e a formação de seus professores no atendimento educacional especializado. Plures Humanidades, Ribeirão Preto, v.14, n.1, p.217-243, 2013.

FELICIO, N.C.; FANTACINI, R. A. F.; TOREZAN, K. R. Atendimento educacional especializado: reflexões acerca da formação de professores e das políticas nacionais. Revista Eletrônica de Educação, São Carlos, v.10, n.3, p.139-154, 2016.

FERREIRA, N.S. A. As pesquisas denominadas "estado da arte". Educação \& Sociedade, São Paulo, v.23, n.79, p.252-272, 2002.

FOUCAULT, M. O sujeito e o poder. In: DREYFUS, Hubert L. Michel Foucault, uma trajetória filosófica: para além do estruturalismo e da hermenêutica. Trad. Vera Porto-Carrero. Rio de Janeiro: Forense Universitária, 1995, p.231-249. 
FOUCAULT, M. Em defesa da sociedade: curso no Collège de France (1975 - 1976). Trad. Eduardo Brandão. São Paulo: Martins Fontes, 1999.

FOUCAULT, M. Nascimento da biopolítica: curso dado no Collège de France (1978-1979). Trad. Eduardo Brandão. São Paulo: Martins Fontes, 2008a.

FOUCAULT, M. Segurança, território e população. Trad. Eduardo Brandão. São Paulo: Martins Fontes, 2008b.

GALLO, S. Infância e resistência: resistir a quê? Leitura: Teoria \& Prática, Campinas, v.31, n.61, p.199-211, nov.2013.

GONÇALVES, A. M. O trabalho docente no atendimento educacional especializado: a apreensão das representações sociais. Moara, Belém, n.45, p.94-107, 2016.

HAGUETTE, T. M. F. Metodologias qualitativas na sociologia. 4. ed. Petrópolis: Vozes, 1995.

KAPITANGO-A-SAMBA, K. K.; HEINZEEN, V. A. Formação de professores em tecnologia assistiva para atendimento educacional especializado em salas de recursos multifuncionais: inclusão ou exclusão? Revista de Educação do Vale do Arinos, Juara, v.1, n.1, p.47-76, 2014.

LAZZARATO, M. La fabrique de I'homme endetté: essai sur la condition néolibérale. Paris: Éditions Amsterdam, 2011.

LIMA, H. C.; GAMA, R. P. Formação continuada de professores de matemática com enfoque nas práticas formativas: um estudo das pesquisas acadêmicas. Periódico Horizontes, Itatiba, v.37, p.1-29, 2019.

LUZ, L. F.; DINIZ, J. C.; LAFONTAINE, T. C. Atendimento educacional especializado para alunos surdos: uma análise sobre a formação do profissional da sala de recursos. In: FÓRUM INTERNACIONAL DE PEDAGOGIA, 8., 2016, Imperatriz. Anais... Imperatriz: Universidade Federal do Maranhão, 2016. p.1-6.

MARINHO, M. F. B. Políticas de inclusão e atendimento educacional especializado no contexto amazônico: desafios para a formação de professores. In: ENCONTRO NACIONAL DE DIDÁTICA E PRÁTICA DE ENSINO, 17., 2014, Fortaleza. Anais... Fortaleza: Universidade Estadual do Ceará, 2014. 1 E-book. p.295-299.

NEGRI, A.; HARDT, M. Declaração: isto não é um manifesto. Trad. Carlos Szlak. São Paulo: N-1, 2014.

NOZU, W. C. S.; BRUNO, M. M. G. Política de (con)formação de professores para o atendimento educacional especializado: estratégias de governamentalidade neoliberal. In: ENCONTRO DA ASSOCIAÇÃO BRASILEIRA DE PESQUISADORES EM EDUCAÇÃO ESPECIAL, 8., 2013, Londrina. Anais... Londrina: Universidade Estadual de Londrina, 2013. p.1229-1240. 
OSTI, A. Atendimento educacional especializado: parceria entre escola e universidade pela inclusão e formação docente. In: CONGRESSO NACIONAL DE FORMAÇÃO DE PROFESSORES, 2.; CONGRESSO ESTADUAL PAULISTA SOBRE FORMAÇÃO DE EDUCADORES, 12., 2011, Águas de Lindóia. Anais... Águas de Lindóia: Universidade Estadual Paulista, 2014. p.8413-8424.

PAIXÃO, E. C. Formação de professores do atendimento educacional especializado para alunos surdos em São Bernardo do Campo. 2016. 263f. Dissertação (Mestrado em Educação) Faculdade de Educação, Universidade de São Paulo, São Paulo, 2016.

PERTILE, E. B.; ROSSETTO, E. Trabalho e formação docente para o atendimento educacional especializado. Revista Ibero-Americana de Estudos em Educação, Araraquara, v.10, n.14, p.1186-1198, 2015.

PLETSCH, M. D. Uma análise sobre o atendimento educacional especializado: políticas, práticas e formação de professores. InterMeio, Campo Grande, v.18, n.36, p.150-161, 2012.

QUEIROZ, J. G. B. A. Formação de professores para o atendimento educacional especializado na rede municipal de ensino de Manaus. 2017. 145f. Dissertação (Mestrado Profissional em Ensino Tecnológico) - Instituto Federal de Educação, Ciência e Tecnologia do Amazonas, Manaus, 2017.

RABELO, L. C. C. Casos de ensino na formação continuada à distância de professores do atendimento educacional especializado. 2016. 305f. Tese (Doutorado em Educação Especial) Centro de Educação e Ciências Humanas, Universidade Federal de São Carlos, São Carlos, 2016.

REVEL, J. Dicionário Foucault. Trad. Anderson Alexandre da Silva. Rio de Janeiro: Forense Universitária, 2011.

ROSSETTO, E. Formação do professor do atendimento educacional especializado: a educação especial em questão. Revista Educação Especial, Santa Maria, v.28, n.51, p.103-116, 2015.

SANTOS, J. D. Formação continuada: cartas de alforria \& controles de regulação. 2006. 171f. Tese (Doutorado em Educação) - Programa de Pós-Graduação em Educação, Universidade Federal do Rio Grande do Sul, Porto Alegre, 2006.

SILUK, A. C. P.; PAVÃO, S. M. O. Educação especial: práticas pedagógicas a distância na formação de professores para o atendimento educacional especializado (AEE). Educação Temática Digital, Campinas, v.14, n.2, p.61-74, 2012.

SILVA, F. D. A.; SOUZA, V.A.; BUIATTI, V. Formação docente: reflexões de participantes do curso de atendimento educacional especializado para alunos surdos. In: SEMINÁRIO NACIONAL DE EDUCAÇÃO ESPECIAL, 6.; ENCONTRO DE PESQUISADORES EM EDUCAÇÃO ESPECIAL E INCLUSÃO ESCOLAR, 5., 2014, Uberlândia. Anais... Uberlândia: UFU, 2014. p.1-15.

SILVA, J. H.; BRUNO, M. M. G. Formação dos professores para o atendimento educacional 
especializado em contexto indígena. Linhas críticas, Brasília, v.22, n.48, p.346-366, 2016.

SILVEIRA, R. M. H. A entrevista na pesquisa em educação: uma arena de significados. In: COSTA, M. V. (Org.). Caminhos Investigativos II: outros modos de pensar e fazer pesquisa em educação. Rio de Janeiro: DP\&A, 2002, p.119-142.

VEIGA-NETO, A. Crise da modernidade e inovações curriculares: da disciplina para o controle. Sísifo, Feira de Santana, n.7, p.141-150, set./dez. 2008.

VINENTE, S.; OLIVEIRA, S. S. B. Implementação do atendimento educacional especializado e a formação de gestores na capital amazonense. Revista Ibero-Americana de Estudos em Educação, Araraquara, v.12, n.1, p.507-528, 2017.

Recebido em junho 2019.

Aprovado em março 2020. 